\title{
Patterns of Medication Utilization and Costs Associated with the Use of Etanercept, Adalimumab, and Ustekinumab in the Management of Moderate-to-Severe Psoriasis
}

\author{
Steven R. Feldman, MD; Yang Zhao, PhD; Prakash Navaratnam, RPh, MPH, PhD;
} Howard S. Friedman, PhD; Jackie Lu, PharmD, MS; and Mary Helen Tran, PharmD, MBA

\begin{abstract}
BACKGROUND: Dose escalations of biologic agents may be attempted in the management of moderate-to-severe psoriasis. This has implications for the real-world cost of treatment.

OBJECTIVE: To examine the utilization patterns and costs associated with the use of etanercept, adalimumab, and ustekinumab among patients with moderate-to-severe psoriasis.

METHODS: This was a retrospective cross-sectional study. Patients with 2 or more medical claims with a diagnosis of psoriasis (excluding psoriatic arthritis) who were enrolled in large employer-sponsored health plans (including a pharmacy benefit) in the United States from January 2007 to March 2012 were identified and extracted from the MarketScan Commercial Encounters Database. Patients aged at least 18 years were required to have 2 or more pharmacy claims for etanercept, adalimumab, or ustekinumab; the index date was the first biologic fill date. Demographics and comorbidities were identified during the 1-year pre-index period, and medication utilization and costs were evaluated in the 1-year post-index period after a titration period according to the product prescribing information (2 weeks to 12 weeks). Medication utilization parameters such as dose escalation, dose reduction, persistence, switching, discontinuation, and restarts were assessed at 6,9 , and 12 months from the end of the dose titration window.
\end{abstract}

RESULTS: A total of 4,309 patients were included with a mean average age of 46 years, and $55 \%$ were male. Fifty-seven percent of the patients were started on etanercept, $39 \%$ on adalimumab, and $5 \%$ on ustekinumab. Patients had substantial dose escalation rates (etanercept: $41 \%$; adalimumab: $37 \%$; ustekinumab: $36 \%, P<0.05)$ and discontinuation rates (etanercept: $35 \%$; adalimumab: $27 \%$; ustekinumab: $16 \%, P<0.05$ ) over the 12-month post-titration period. Many patients also restarted the same biologic (etanercept: $37 \%$; adalimumab: $10 \%$; ustekinumab: $6 \%, P<0.05$ ) or switched to another biologic (etanercept: $15 \%$; adalimumab: $10 \%$; ustekinumab: $5 \%, P<0.05$ ) over the 12-month post-titration period. The persistence rates over 12 months were $19 \%, 53 \%$, and $71 \%$ for etanercept, adalimumab, and ustekinumab, respectively $(P<0.05)$. Close to one-third of the patients at 6 months and $39 \%$ at 12 months postdose titration experienced a dose escalation. Approximately half of the patients who experienced a dose escalation also had a discontinuation or a dose reduction over the 12-month post-titration period.

CONCLUSIONS: Over one-third of psoriasis patients experienced a dose escalation of their biologic agents, and most of the dose escalation occurred during the first 6 months. Restarting, switching, and discontinuing index biologics were also common.

J Manag Care Spec Pharm. 2015;21(3):201-09

Copyright $\odot 2015$, Academy of Managed Care Pharmacy. All rights reserved.

\section{What is already known about this subject}

Psoriasis is a chronic and painful skin disease that is associated with increased risk of comorbid medical conditions and reduced health-related quality of life.

The cost of treating psoriasis is substantial, owing to the chronic nature of the disease, the need for health care utilization, the presence of comorbidities that also require treatment, and lost work productivity.

Biologic agents represent an increasingly widely used treatment option for patients with moderate-to-severe psoriasis.

\section{What this study adds}

This retrospective health care claims database analysis provides a real-world perspective on the dosing patterns associated with biologic therapies (etanercept, adalimumab, and ustekinumab) for the management of moderate-to-severe psoriasis.

Dose escalation, dose reduction, restarting, switching, and discontinuation of biologics were common.

Many patients who initiated biologic therapy with etanercept, adalimumab, or ustekinumab experienced medication disruptions in the first year after initiating the therapy.

1 soriasis is a chronic and painful condition of the skin, most often appearing as red and scaly patches accompanied by itching and sometimes bleeding. ${ }^{1}$ It is the most prevalent immune-mediated disease in the United States, affecting as many as 7.5 million people. ${ }^{1}$ The impact of psoriasis goes beyond its dermatologic manifestations. Psoriasis is associated with an elevated risk of serious and chronic conditions, including diabetes mellitus, stroke, hypertension, cardiovascular disease, and cancer. ${ }^{2-5}$ Furthermore, lower quality of life and higher rates of anxiety, depression, and psychosocial impairment are observed in psoriasis patients when compared with the general population. ${ }^{6,7}$ Psychological interpersonal difficulties impact all aspects of daily life for psoriasis patients; anxiety and pathological worry occur in at least one-third of these patients.?

Given that psoriasis most often strikes between the ages of 15 and 35, patients will require lifelong attention and 
treatment. ${ }^{1}$ Consequently, the economic burden of psoriasis is considerable for patients and the health care system. In 2008, the U.S. total direct medical costs and indirect costs (i.e., lost productivity) of psoriasis were estimated at $\$ 11.25$ billion annually, with lost time at work accounting for $40 \%$ of the economic burden. ${ }^{8}$ People with psoriasis have significantly higher health care resource utilization and costs than the general population. ${ }^{9}$ Additionally, the comorbid conditions in patients with psoriasis represent a substantial economic burden to society. ${ }^{10}$

According to American Academy of Dermatology psoriasis treatment guidelines, several treatment options are available for psoriasis patients depending on the severity of the disease. ${ }^{11}$ Patients with mild psoriasis are often treated with prescription and over-the-counter topical moisturizers, creams, and ointments. Moderate and severe psoriasis is often treated with topical medications as well as other treatments, including phototherapy, systemic pharmaceuticals (i.e., acitretin, cyclosporine, and methotrexate), and biologic agents. ${ }^{1}$

Since their introduction more than a decade ago, biologic agents have represented an increasingly widely used treatment option for patients with moderate-to-severe psoriasis who have not responded to or have experienced side effects from other treatments. ${ }^{12}$ These agents act by blocking the action of specific types of immune cells, such as the T cell, or by blocking proteins in the immune system, such as tumor necrosis factor-alpha (TNF-alpha) or interleukins 12 and 23 (IL-12 and IL-23). ${ }^{1}$ Etanercept and adalimumab are 2 of the most commonly used TNF-alpha blockers, but both agents may increase risk of serious infections, and malignancies have been reported with both. ${ }^{13,14}$ A recent survey by the National Psoriasis Foundation reported that, in 2011, approximately 12\% of psoriasis patients were using either etanercept or adalimumab. ${ }^{12}$ This survey also found that $50 \%$ of patients were dissatisfied with their psoriasis treatment. The primary reasons for discontinuation of biologic agents were lack of efficacy (25\%) and adverse effects (16\%). ${ }^{12}$ Ustekinumab is a commonly used IL-12 and IL-23 antagonist. Although randomized trials have demonstrated the efficacy of ustekinumab in psoriasis, there has been concern that ustekinumab may increase the risk of infections or malignancy ${ }^{15}$ or increase the risk of cardiovascular events. ${ }^{16}$ A recent review of pooled data from phase 2 and phase 3 trials of ustekinumab, however, did not reveal an increased risk of these events. ${ }^{17}$

Although the standard approved dosing regimens of these biologic agents have been established in large, randomized, double-blind, placebo-controlled clinical trials, clinical experience in real-world practice settings suggests that off-label dosing regimens are frequently used and clinically relevant. ${ }^{18-26}$ Off-label dosing regimens can be broadly categorized as dose escalations, dose reductions, intermittent therapy, or interruptions in therapy followed by retreatment. ${ }^{18}$ The reasons for these dose adjustments may be to improve efficacy in very severe cases, address increasing dose tolerance over time, manage patients with obesity for whom standard dosing may not be adequate, or prepare for surgeries with significant infectious risks. ${ }^{18}$ A recent systematic review by Brezinski et al. (2012) identified 23 studies in which off-label dosing regimens of etanercept, adalimumab, or ustekinumab were being used in clinical practice to address issues with nonresponders or gaps in efficacy. ${ }^{18}$ The authors found that, among nonresponders, the use of off-label dosing regimens (i.e., dose escalations) resulted in greater efficacy than standard dosing regimens. ${ }^{18}$

Given the high costs associated with biologic agents, the real-world dosing of these agents may have significant cost implications for clinicians and formulary decision makers within managed care organizations. The variations in dosing schedules combined with the influence of gaps in therapy, discontinuation, or switching between agents within a given class make it challenging for clinicians and other providers to determine the true economic impact of these agents.

The primary objective of this study was to examine the medication utilization patterns (dosing, persistence, switching, discontinuation, restarts), patient demographics, and clinical characteristics associated with the use of etanercept, adalimumab, and ustekinumab among patients with moderate-tosevere psoriasis in a real-world setting. A secondary objective of the study was to examine the time to dose escalation for each of the study biologics.

\section{Methods}

\section{Study Design}

Retrospective analyses were performed using health care claims data from a large U.S. employer-based claims database, the MarketScan Commercial Encounters Database, between January 2007 and March 2012. Nearly 29 million individuals are included in the database, which encompasses employees, their spouses, and dependents who are covered by employersponsored private health insurance, including a pharmacy benefit. The MarketScan Commercial Encounters Database provides data on hospitalizations, inpatient and outpatient services, emergency room visits, inpatient and outpatient diagnoses (using International Classification of Diseases, Ninth Revision, Clinical Modification [ICD-9-CM] codes), outpatient prescription drugs, and costs. This database fully integrates the pharmacy and medical claims records at the patient level and allows for the tracking of patient information across sites, across providers, and over time. Additionally, the MarketScan Commercial Encounters Database has broad geographic coverage at the national and state levels. This database is compliant with the Health Insurance Portability and Accountability Act and contains synthetic identifiers to protect the privacy of individual patients and data contributors. 
Patterns of Medication Utilization and Costs Associated with the Use of Etanercept, Adalimumab, and Ustekinumab in the Management of Moderate-to-Severe Psoriasis

\begin{tabular}{l|l|l}
\hline \multicolumn{1}{c}{ TABLE 1 } & $\begin{array}{l}\text { Dosage Strengths and Dose } \\
\text { Titration Schedules for Etanercept, } \\
\text { Adalimumab, and Ustekinumab }\end{array}$ \\
\hline & \multicolumn{1}{|c}{ Induction } & $\begin{array}{l}\text { Time to } \\
\text { Maintenance Dose }\end{array}$ \\
\hline Etanercept & $\begin{array}{l}50 \mathrm{mg} \text { twice weekly for 3 months } \\
\text { followed by 50 mg per week }\end{array}$ & $\begin{array}{l}12 \text { weeks from } \\
\text { initiation }\end{array}$ \\
\hline Adalimumab & $\begin{array}{l}80 \mathrm{mg} \text { initial dose followed by 40 mg } \\
1 \text { week after initial dose }\end{array}$ & $\begin{array}{l}\text { 2 weeks from } \\
\text { initiation }\end{array}$ \\
\hline Ustekinumab & $\begin{array}{l}<100 \mathrm{~kg}(220 \mathrm{lb}): 45 \mathrm{mg} \text { initially } \\
\text { and 4 weeks later; then 45 mg every } \\
12 \text { weeks }\end{array}$ & $\begin{array}{l}\text { 4 weeks after } \\
\text { initiation }\end{array}$ \\
\hline
\end{tabular}

$\mathrm{kg}=$ kilogram; $\mathrm{lb}=$ pounds; $m g=$ milligram .

\section{Patient Selection}

Adults who were at least aged 18 years with moderate-tosevere psoriasis as determined by treatment with etanercept, adalimumab, or ustekinumab (which are only indicated for treatment of moderate-to-severe disease) were included in the study if they had 2 or more pharmacy claims for these agents between January 1, 2007, and March 20, 2012. Ustekinumab received U.S. Food and Drug Administration (FDA) approval in September 2009, and data for the period from January 2007 through August 2009 were used to capture etanercept and adalimumab patients. The first fill date was defined as the index date, and the biologic received on this date was referred to as the index biologic. Patients were required to have 2 or more distinct medical claims with a diagnosis of psoriasis (ICD-9-CM code 696.1) on or within 1 year prior to the index date. Patients with a diagnosis of psoriatic arthritis (ICD-9-CM code 696.0) were excluded from the analysis. Patients were required to have been continuously enrolled in the health plan for at least 1 year before the index date and 1 year plus the titration window after the index date. The titration window was defined as the period from the initiation of therapy to the end of the recommended induction period according to the product label. Dosage strengths and titration schedules for these agents can be found in Table 1 .

Patients were excluded for the following reasons: (a) if they received any biologic agent within 1 year before the index date; (b) if they had a concomitant diagnosis of human immunodeficiency virus infection (ICD-9-CM code 042.x) or cancer (ICD9-CM code 140.X-239.x) in the 1-year pre-index period; (c) if they had records with missing dosing information (i.e., missing quantity dispensed or days' supply information) during the study period; or (d) if they had fewer than 2 medical claims with a diagnosis of psoriasis in the pre-index period. Patients with the following diagnoses in the 1-year pre-index period were also excluded to ensure that the biologic agents examined here were used to treat psoriasis: rheumatoid arthritis (ICD9-CM code 714.2), juvenile idiopathic arthritis (ICD-9-CM code 714.3), ankylosing spondylitis (ICD-9-CM code 720.0), Crohn's disease (ICD-9-CM code 555.2), or ulcerative colitis (ICD-9-CM code 556.8).

\section{Outcomes Assessments}

The primary outcomes for this analysis were medication utilization patterns for etanercept, adalimumab, and ustekinumab among patients with moderate-to-severe psoriasis. These outcomes were evaluated in the 1-year post-index period after the dose titration window. Other outcomes included demographics, comorbidities as measured by the Charlson Comorbidity Index (CCI), and all-cause total health care costs (adjusted to year 2012 U.S. dollars based on the Medical Care component of the Consumer Price Index). These outcomes were analyzed during the 1-year pre-index period.

The medication utilization patterns examined included dose escalation, dose reduction, persistence, switching, discontinuation, and restarting therapy, as well as the time to dose escalation. Dosing for each biologic was measured in average weekly dose, which was a function of the prescribed strength (based on National Drug Code and J-code descriptors) and the interval between the preceding dose and the next refill. Dose escalation (or reduction) was defined as the patient's experiencing a dose increase (or decrease) of at least 25\% following the titration window. The $25 \%$ threshold was chosen based on clinical expert opinion and a literature review of the various methodologies used to define a minimal clinically important difference in dose change associated with biologic agents. ${ }^{27-29}$ The review revealed that the range for a minimal clinically important difference was between $15 \%$ and $50 \% .{ }^{27-29}$ Patients who had an average weekly dose in the post-titration window that exceeded this threshold when compared with their baseline dose (dose at end of titration window) were deemed to have had a dose escalation. In addition, the time to dose escalation (in days) was examined for each biologic over the follow-up period (12 months after the end of the titration window).

Medication persistence outcomes were determined based on the permissible treatment gaps for each study biologic. A treatment gap was defined as the time between the preceding fill and the time to the next refill. Permissible treatment gaps were defined as 4 weeks for etanercept, 8 weeks for adalimumab, and 18 weeks for ustekinumab, based on clinical expert opinion. Patients were considered to be persistent if they had no treatment gaps that exceeded the specified time thresholds. Patients were deemed to have switched therapy if they had a treatment gap exceeding the specified time threshold for the index biologic and had initiated a new biologic agent after the preceding fill. If patients were not persistent on the index biologic and there were no biologics identified following the preceding fill, patients were deemed to have discontinued the therapy. If a patient had a treatment gap that exceeded the specified time thresholds and subsequently re-initiated the 
Patterns of Medication Utilization and Costs Associated with the Use of Etanercept, Adalimumab, and Ustekinumab in the Management of Moderate-to-Severe Psoriasis

\section{FIGURE 1 Patient Selection}

Inclusion Criteria

Unique Patients

1. Two or more medication fills for etanercept, adalimumab, or ustekinumab

155,982

$\downarrow$

2. Two or more distinct medical claims with a diagnosis of psoriasis within 1 year before index date $^{a}$

3. Aged $\geq 18$ years

4. Continuously enrolled at least 1 year before the index date and 1 year plus the titration window after the index date ${ }^{b}$

Exclusion Criteria

1. Receiving any biologic within 1 year before index date

2. Diagnosis of other biologic agent prescribing condition within 1 year before index date ${ }^{c}$

3. Diagnosis of HIV or cancer within 1 year before index date

4. Missing records for quantity dispensed or days' supply

5. Only 1 pre-index day with a diagnosis of psoriasis

5,563

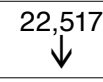

22,165

$\downarrow$

11,100

$\downarrow$

7,321

$\downarrow$

7,274

$\downarrow$

5,746

$\downarrow$

(final sample size)

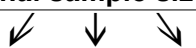

Etanercept Adalimumab Ustekinumab

$n=2,452 \quad n=1,662 \quad n=195$

Data Source: MarketScan Commercial Encounters Database. Study period: January 2007 to March 2012.

aThe first fill date was defined as the index date, and the biologic received on this date was referred to as the index biologic.

${ }^{b}$ The titration window was defined as the period from the initiation of therapy to the end of the induction period as stated in the product label.

'Patients with a record of the following diagnoses where biologic agents may be utilized in the 1-year pre-index period were excluded: rheumatoid arthritis, juvenile

idiopathic arthritis, ankylosing spondylitis, Crohn's disease, and ulcerative colitis.

HIV = human immunodeficiency virus.

same index biologic agent, the patient was deemed to have restarted therapy.

\section{Data Analyses}

Patients were assigned to 1 of 3 unique biologic cohorts based on their index biologic agents. Demographics and comorbidities were analyzed during the 1-year pre-index period to examine differences in patient characteristics between the biologic cohorts. Medication utilization parameters were evaluated in the 1-year post-index period after the titration period ( 2 to 12 weeks, depending on the prescribing information); chi-square testing was used to examine between-group differences for dose escalation, dose reduction, persistence, restart, switching, and discontinuation. Dose escalation was also assessed at 6 and 9 months from the end of the dose titration window. Total health care costs were annualized and examined during the 1 -year pre-index period. Sensitivity analyses were performed to determine the consequences of alternative assumptions about the threshold definition (i.e., change from $25 \%$ dose increase to other threshold) of dose escalation.

\section{Results}

\section{Patient Characteristics}

A total of 4,309 patients met the study criteria and were included in the analysis (Figure 1). The selection process identified 2,452 (56.9\%) receiving etanercept, 1,662 (38.6\%) receiving adalimumab, and 195 (4.5\%) receiving ustekinumab.

The majority of patients were male $(55.5 \%)$, and the average age of patients was 45 years (Table 2). Among all 3 patient groups, ustekinumab patients were older, more likely to have seen a dermatologist, and more likely to have used mail-order prescriptions. In general, all patients had similar comorbidity scores as measured by the CCI. Most patients resided in the South (43\%) and North Central (28.5\%) regions of the United States. Mean total costs for all patients were $\$ 30,568$.

\section{Dosing Patterns}

Dose escalation rates over the 12-month follow-up period were substantial (Table 3). Among all study patients, 33.0\% experienced a dose escalation at 6 months, $37.2 \%$ at 9 months, and $39.1 \%$ at 12 months postdose titration. Dose escalation rates at 
Patterns of Medication Utilization and Costs Associated with the Use of Etanercept, Adalimumab, and Ustekinumab in the Management of Moderate-to-Severe Psoriasis

\section{TABLE 2 Patient Characteristics}

\begin{tabular}{|c|c|c|c|c|}
\hline Characteristic & All & Etanercept & Adalimumab & Ustekinumab \\
\hline Patients, n (\%) & $4,309(100.0)$ & $2,452 \quad(56.9)$ & $1,662 \quad(38.6)$ & $195 \quad(4.5)$ \\
\hline Age, years, mean (SD) & $45.7 \quad(12.9)$ & $45.5 \quad(12.9)$ & $45.5 \quad(12.7)$ & $49.9 \quad(13.5)$ \\
\hline Male, \% & 55.5 & 55.1 & 56.0 & 56.1 \\
\hline $\mathrm{CCI}$, mean $(\mathrm{SD})^{\mathrm{a}}$ & $0.4 \quad(0.8)$ & $0.4 \quad(0.8)$ & $0.4 \quad(0.8)$ & $0.6 \quad(1.3)$ \\
\hline \multicolumn{5}{|l|}{ Region, \% } \\
\hline Northeast & 11.7 & 11.6 & 11.4 & 14.4 \\
\hline North Central & 28.5 & 29.0 & 27.9 & 27.2 \\
\hline South & 43.0 & 41.0 & 46.2 & 41.5 \\
\hline West & 15.9 & 17.5 & 13.5 & 15.9 \\
\hline Unknown & 1.0 & 0.9 & 1.0 & 1.0 \\
\hline \multicolumn{5}{|l|}{ Index year, \% } \\
\hline 2007 & 16.5 & 24.9 & 6.1 & 0.0 \\
\hline 2008 & 28.0 & 31.9 & 25.6 & 0.0 \\
\hline 2009 & 24.5 & 23.0 & 28.6 & 8.2 \\
\hline 2010 & 23.4 & 15.9 & 30.6 & 54.9 \\
\hline 2011 & 7.6 & 4.3 & 9.0 & 36.9 \\
\hline Percentage with pre-index mail-order records, $\%$ & 21.8 & 20.7 & 22.1 & 32.8 \\
\hline Percentage with dermatologist as physician specialty, $\%$ & 82.2 & 81.4 & 82.3 & 89.7 \\
\hline Mean total costs, ${ }^{\mathrm{b}} \$$ & 30,568 & 28,018 & 31,369 & 55,794 \\
\hline
\end{tabular}

aThe CCI was used to define the comorbid status of each patient. A score of zero represents no serious existing comorbid conditions.

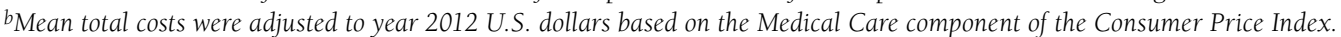

CCI $=$ Charlson Comorbidity Index; $S D=$ standard deviation .

12 months were $41.0 \%$ for etanercept, 36.6\% for adalimumab, and $35.9 \%$ for ustekinumab $(P<0.05)$. The median number of days to dose escalation was lowest in the adalimumab cohort (55 days) and highest in the ustekinumab cohort (108 days).

Dose reduction rates were substantial, with $50.1 \%$ of patients experiencing a dose reduction over the 12-month follow-up period in the full population and $48.7 \%, 53.7 \%$, and $37.4 \%$ in the etanercept, adalimumab, and ustekinumab cohorts, respectively $(P<0.05)$. Of the 1,355 nonswitch patients who experienced a dose escalation over the 12-month follow-up period, $51 \%$ of these patients also experienced a discontinuation or dose reduction (Figure 2).

\section{Persistence Patterns}

Overall, the persistence rate for the 12-month follow-up period for all biologic cohorts was 34.6\% (Figure 3). The persistence rate was lowest for etanercept (19.0\%) and highest for ustekinumab (70.8\%; $P<0.05)$. Among patients who experienced a treatment gap, many restarted the same biologic $(25.3 \%)$ or switched to another biologic therapy (12.5\%). Approximately $30.8 \%$ of patients discontinued their index biologic therapies over the 12-month follow-up period: $34.5 \%$ in the etanercept cohort, $27.2 \%$ in the adalimumab cohort, and $15.9 \%$ in the ustekinumab cohort $(P<0.05)$. Among all the cohorts, more etanercept patients experienced dose reductions, switches, discontinuations, and restarts, followed by adalimumab and ustekinumab $(P<0.05)$.
TABLE 3 Dose Escalation and Reduction Patterns by Index Biologic Cohort

\begin{tabular}{|c|c|c|c|c|}
\hline & $\begin{array}{c}\text { All } \\
\mathrm{N}=4,309\end{array}$ & $\begin{array}{c}\text { Etanercept } \\
\mathbf{n}=2,452\end{array}$ & $\begin{array}{c}\text { Adalimumab } \\
\mathrm{n}=1,662\end{array}$ & $\begin{array}{c}\text { Ustekinumab } \\
\mathrm{n}=195\end{array}$ \\
\hline \multicolumn{5}{|c|}{ Patients with dose } \\
\hline \multicolumn{5}{|c|}{\begin{tabular}{l|l} 
Escalation, \% & \\
\end{tabular}} \\
\hline at 6 months & 33.0 & 34.3 & 31.5 & 28.2 \\
\hline at 9 months ${ }^{a}$ & 37.2 & 39.3 & 34.5 & 33.3 \\
\hline at 12 months $^{\mathrm{a}}$ & 39.1 & 41.0 & 36.6 & 35.9 \\
\hline \multicolumn{5}{|c|}{ Patients with dose } \\
\hline \multicolumn{5}{|c|}{ Reduction, \% } \\
\hline at 12 months $^{\mathrm{a}}$ & 50.1 & 48.7 & 53.7 & 37.4 \\
\hline \multicolumn{5}{|c|}{ Median days to dose $\mathrm{e}^{\mathrm{b}}$} \\
\hline Escalation & & 61 & 55 & 108 \\
\hline
\end{tabular}

Sensitivity analyses completed for nonswitch patients only revealed that the results were sensitive to assumptions regarding the threshold definition of dose escalation, with a higher threshold definition resulting in fewer patients experiencing a dose escalation, as expected (Figure 4). For example, at the $25 \%$ threshold used in this study to define dose escalation, the rate of dose escalations was approximately $37 \%$. When the threshold definition was varied to $50 \%, 23 \%$ of patients were identified as having experienced a dose escalation. 


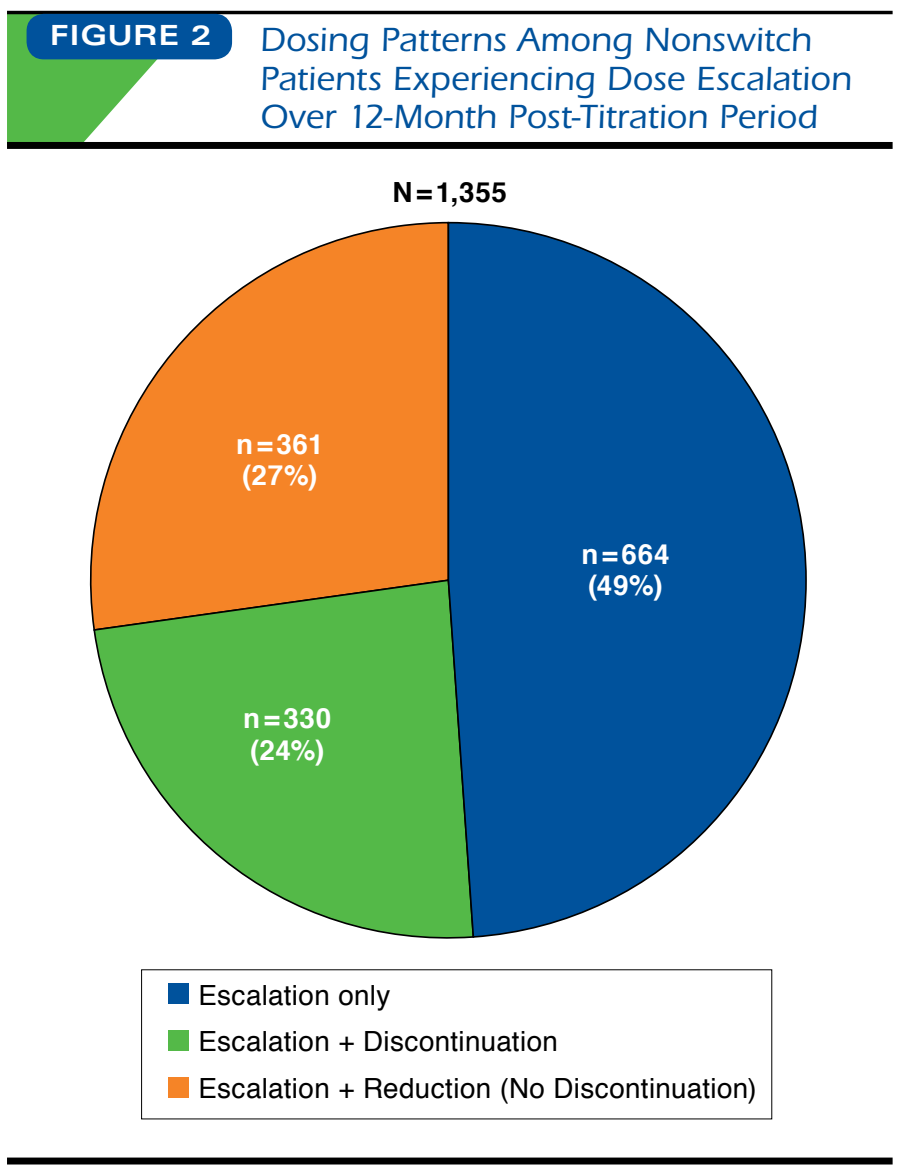

\section{Discussion}

Analyses of the real-world medication utilization and costs of biologic agents have revealed that managing moderate-tosevere psoriasis is costly and complex. This study found that disruptions in therapy, defined as dose escalations, dose reductions, switches, discontinuations, and restarts, were common, since half of the patients experienced some form of disruption during the 12 months after starting a biologic. One-third of the patients in our analysis experienced a dose escalation within 6 months of therapy initiation, suggesting that inadequate response to or dissatisfaction with standard dosing of biologic agents is common among moderate-to-severe psoriasis patients. Although dose escalation rates were similar for all of the biologics examined, the time to dose escalation varied substantially across biologics. The decision to increase dose might be influenced by many factors, including efficacy, safety, and dosing frequency. Since the reason for dose escalation was not documented in the database examined here, future studies might be needed to focus on this area. Furthermore, dose escalations were commonly followed by dose reductions or discontinuation, implying that higher-than-standard doses of the biologics studied might not be sustainable.
The overall low persistence rates highlight an unmet need in existing biologic treatment for psoriasis. Only about onethird of patients were persistent with their biologic therapies by the end of the 12-month follow-up period, and one-third of patients ceased treatment with biologics. The remaining patients were either restarted on the same biologic or switched to another agent. Interestingly, restart was more common than switching, which suggests that physicians and patients were inclined to modify treatment using the same biologic rather than try a different biologic agent.

The results of our study are consistent with those of other recent claims analyses evaluating the annualized costs and medication outcomes of TNF-alpha inhibitors for managing psoriasis in commercially insured patient populations. ${ }^{30-33}$ Bonafede et al. (2012) examined the real-world medication utilization patterns (persistence, switching, restart, and discontinuation) from 2005 to 2009 for etanercept and adalimumab in patients with psoriasis, using the same MarketScan Commercial Encounters database. ${ }^{33}$ Their results demonstrated that disruptions in biologic therapy were quite common (persistence rate of $22 \%$ for etanercept and $33 \%$ for adalimumab). ${ }^{33}$ However, an important distinction of our study is that it took a comprehensive approach to analyzing medication utilization outcomes, including dose escalations and dose reductions as well as persistence, switching, restart, and discontinuation. Other claims analyses also have taken a less extensive approach than ours to the assessment of medication utilization outcomes.

Recent biologic utilization studies from Europe also examined discontinuation of these agents. ${ }^{34-36}$ Using a large prospective registry in Denmark, Gniadecki et al. (2015) found that $41 \%$ of patients taking either adalimumab, etanercept, infliximab, or ustekinumab had discontinued treatment over 10 years of follow-up..$^{34}$ Van den Reek et al. (2014) ${ }^{35}$ and LópezFerrer et al. (2013), ${ }^{36}$ examining adalimumab utilization at single centers, found discontinuation rates of 39\% over 4.5 years of follow-up in the Netherlands and $41 \%$ over 5 years in Spain, respectively. Although these rates of discontinuation are higher compared with our findings, the follow-up periods in these studies were 4.5 to 10 years, which were longer than our 1-year post-titration follow-up period. ${ }^{34-36}$

Overall, our study showed that the management of moderate-to-severe psoriasis requires intensive health care resources. The frequency of dosing practices that deviate from standard regimens suggests that there is a large unmet need for effective and sustainable treatment despite the already substantial economic burden placed on patients with psoriasis and on the health care system.

\section{Limitations}

This study was subject to several limitations. First, information that may affect study outcomes, such as measures of disease 
Patterns of Medication Utilization and Costs Associated with the Use of Etanercept, Adalimumab, and Ustekinumab in the Management of Moderate-to-Severe Psoriasis

FIGURE 3 Persistence, Restart, Switching, and Discontinuation Rates Over 12-Month Post-Titration Period ${ }^{\text {a }}$

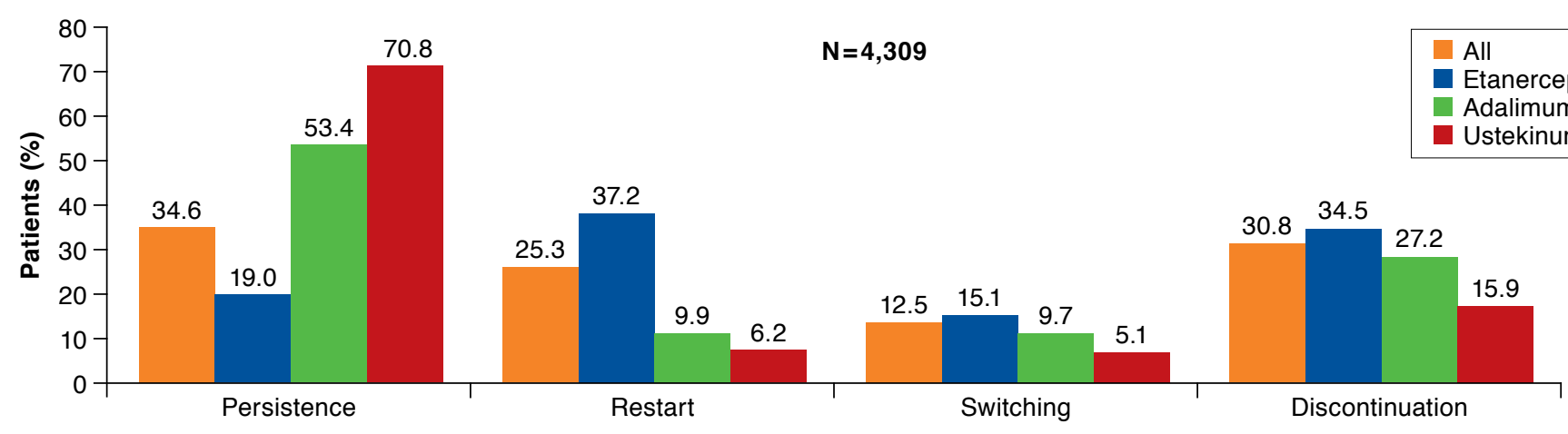

$P<0.05$ for all statistical comparisons.

aPatients may experience multiple utilization patterns and thus can be counted more than once.

severity, socioeconomic status, concurrent immunosuppressants or other agents used to treat psoriasis, and allergy profiles were either not readily available in the claims database or not included as part of the data capture. Second, the claims database did not report patients' body weight, which is an important criterion in selecting the ustekinumab dose. As a consequence, dose escalations associated with ustekinumab were inferred based on observations of dose strength and the interval of ustekinumab dosing. Third, the benefit designs of patients' health plans are unknown; data regarding preferred specialty pharmacy, prior authorization requirements, and preferred product tiers were unavailable. Fourth, as with most retrospective claims analyses, it is possible that there may have been miscoding of diagnoses, resource use services, or procedures, leading to potential errors in estimation. Independent confirmation of coding or chart review of individual patient records was not possible. Fifth, the patient cohorts were determined from a database encompassing employees, their spouses, and dependents who were covered by large employersponsored private health insurance plans. As a result, the findings of this study may not be generalizable to the entire U.S. population, particularly individuals who are covered under Medicaid or Medicare. Sixth, we retrospectively examined biologic usage from January 2007 through March 2012, but ustekinumab received FDA approval in September 2009. It is possible, therefore, that its use was underrepresented in the patients included in our sample. More up-to-date studies may be needed to confirm our findings with this agent.

Most of these limitations are inherent to any claims database analysis and do not preclude the development of clinically relevant conclusions about the real-world utilization of biologic agents in the management of patients with moderateto-severe psoriasis.

\section{FIGURE 4 \\ Dose Escalation Rates in Psoriasis Patients by Various Dose Escalation Definitions ${ }^{a}$}

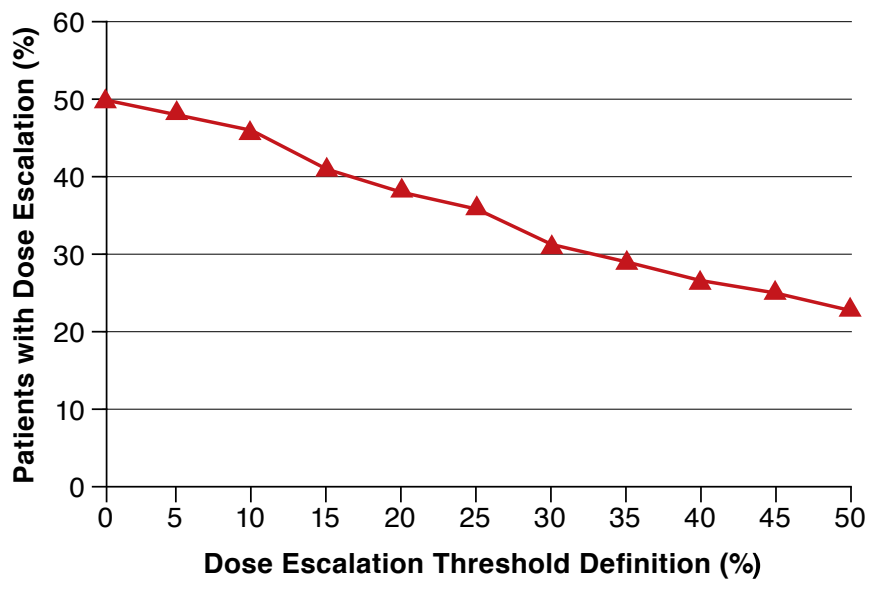

aThe sensitivity analysis was conducted on nonswitch patients only.

\section{Conclusions}

Using a large and recent U.S. administrative claims database, this study examined health care costs and dosing patterns associated with etanercept, adalimumab, and ustekinumab among moderate-to-severe psoriasis patients. Many patients who initiated biologic therapy with etanercept, adalimumab, or ustekinumab experienced disruptions in therapy over the course of 1 year after starting the treatment. Not only did a high proportion of patients undergo dose escalations, but these escalations also occurred soon after treatment initiation, suggesting an inadequacy of standard dosing regimens or disease exacerbation of increased severity. Dose reductions, restarts, switches, and discontinuations of biologics were also common among these patients. 


\section{Authors}

STEVEN R. FELDMAN, MD, is Professor of Dermatology, Wake Forest University, Winston-Salem, North Carolina; YANG ZHAO, $\mathrm{PhD}$, is Director, Health Economics and Outcomes Research, Novartis Pharmaceuticals, East Hanover, New Jersey; JACKIE LU, PharmD, MS, is Regional Clinical Account Director, AstraZeneca, Wilmington, Delaware; and MARY HELEN TRAN, PharmD, MBA, is Associate Vice President, Global Value \& Access, Sanofi, Bridgewater, New Jersey. PRAKASH NAVARATNAM, RPh, MPH, $P h D$, is Senior Partner and Director, Business Development, and HOWARD S. FRIEDMAN, PhD, is Senior Partner, DataMed Solutions, New York, New York.

AUTHOR CORRESPONDENCE: Yang Zhao, PhD, Director, HEOR, U.S. Medical and Drug Regulatory Affairs, Novartis Pharmaceuticals, One Health Plaza, East Hanover, NJ 07936-1080. Tel.: 862.778.3662; Cell: 201.396.2910; Fax: 973.781.2390; E-mail:yang-3.zhao@novartis.com.

\section{DISCLOSURES}

Support for this research was provided by Novartis Pharmaceuticals, East Hanover, New Jersey.

Navaratnam and Friedman are paid consultants for Novartis Pharmaceuticals and are employees of DataMed Solutions. Feldman is a board certified dermatologist on the faculty of the Wake Forest School of Medicine and was engaged by Novartis Pharmaceuticals as a paid clinical expert and scientific advisor for this study. Zhao is an employee of Novartis Pharmaceuticals. Tran and Lu were employees of Novartis Pharmaceuticals Corporation when the study was conducted.

Portions of this work were presented at the 2014 Annual Meeting of the Academy of Managed Care Pharmacy, April 1-4, 2014, Tampa, Florida.

Study concept and design were contributed by Feldman, Zhao, Friedman, Navaratnam, and Tran. Navaratnam and Friedman were responsible for data collection. Data were interpreted by Zhao, Lu, Tran, Navaratnam, and Friedman, with assistance from Feldman. The manuscript was written primarily by Feldman, Zhao, and Navaratnam, with assistance from Lu, Tran, and Friedman. The manuscript was revised by Zhao, Lu, and Tran, assisted by Navaratnam, Friedman, and Feldman.

\section{ACKNOWLEDGMENTS}

Medical writing assistance was provided by Michael Mafilios at Health Economics Associates, and editorial assistance was provided by BioScience Communications. Medical writing and editorial assistance were funded by Novartis Pharmaceuticals.

\section{REFERENCES}

1. National Psoriasis Foundation. Psoriasis overview; Psoriasis statistics. Available at: http://www.psoriasis.org/document.doc?id=215 and http:// www.psoriasis.org/research/science-of-psoriasis/statistics. Accessed February 3, 2015.

2. Kaye JA, Li L, Jick SS. Incidence of risk factors for myocardial infarction and other vascular diseases in patients with psoriasis. Br J Dermatol. 2008;159(4):895-902.

3. Neimann AL, Shin DB, Wang X, Margolis DJ, Troxel AB, Gelfand JM. Prevalence of cardiovascular risk factors in patients with psoriasis. J Am Acad Dermatol. 2006;55(5):829-35.
4. Prodanovich S, Kirsner RS, Kravetz JD, Ma F, Martinez L, Federman DG Association of psoriasis with coronary artery, cerebrovascular, and peripheral vascular diseases and mortality. Arch Dermatol. 2009;145(6):700-03.

5. Solomon DH, Love TJ, Canning C, Schneeweiss S. Risk of diabetes among patients with rheumatoid arthritis, psoriatic arthritis and psoriasis. Ann Rheum Dis. 2010;69(12):2114-17.

6. Kurd SK, Troxel AB, Crits-Christop P, Gelfand JM. The risk of depression, anxiety and suicidality in patients with psoriasis: a population-based cohort study. Arch Dermatol. 2010:146(8):891-95.

7. Langley RG, Krueger GG, Griffiths CE. Psoriasis: epidemiology, clinical features, and quality of life. Ann Rheum Dis. 2005;64(Suppl 2):iil8-23.

8. Fowler JF, Duh MS, Rovba L, et al. The impact of psoriasis on health care costs and patient work loss. J Am Acad Dermatol. 2008;59(5):772-80.

9. Yu AP, Tang J, Xie J, et al. Economic burden of psoriasis compared to the general population and stratified by disease severity. Curr Med Res Opin. 2009;25(10):2429-38.

10. Kimball AB, Guérin A, Tsaneva M, et al. Economic burden of comorbidities in patients with psoriasis is substantial. J Eur Acad Dermatol Venereol. 2011;25(2):157-63.

11. American Academy of Dermatology Work Group, Menter A, Korman NJ, et al. Guidelines of care for the management of psoriasis and psoriatic arthritis: section 6. Guidelines of care for the treatment of psoriasis and psoriatic arthritis: case-based presentations and evidence-based conclusions. J Am Acad Dermatol. 2011;65(1):137-74.

12. Armstrong AW, Robertson AD, Wu J, Schupp C, Lebwohl MG. Undertreatment, treatment trends, and treatment dissatisfaction among patients with psoriasis and psoriatic arthritis in the United States: findings from the National Psoriasis Foundation surveys, 2003-2011. JAMA Dermatol. 2013;149(10):1180-85.

13. Enbrel (etanercept) solution for subcutaneous use. Amgen Inc. Revised November 2013. Available at: http://pi.amgen.com/united_states/enbrel/ derm/enbrel_pi.pdf. Accessed January 13, 2015.

14. Humira (adalimumab) injection, subcutaneous use. AbbVie Inc. Revised December 2014. Available at: http://www.rxabbvie.com/pdf/humira.pdf. Accessed January 13, 2015

15. Stelara (ustekinumab) injection, for subcutaneous use. Janssen Biotech, Inc. Revised March 2014. Available at: http://www.stelarainfo.com/pdf/ PrescribingInformation.pdf. Accessed January 13, 2015.

16. Ryan C, Leonardi CL, Krueger JG, et al. Association between biologic therapies for chronic plaque psoriasis and cardiovascular events: a metaanalysis of randomized controlled trials. JAMA. 2011;306(8):864-71.

17. Reich K, Papp KA, Griffiths CE, et al; ACCEPT investigators. An update on the long-term safety experience of ustekinumab: results from the psoriasis clinical development program with up to four years of follow-up. J Drugs Dermatol. 2012;11(3):300-12.

18. Brezinski EA, Armstrong AW. Off-label biologic regimens in psoriasis: a systematic review of efficacy and safety of dose escalation, reduction, and interrupted biologic therapy. PLoS One. 2012;7(4):e33486.

19. Papp KA, Tyring S, Lahfa M, et al; Etanercept Psoriasis Study Group. A global phase III randomized controlled trial of etanercept in psoriasis: safety, efficacy, and effect of dose reduction. Br J Dermatol. 2005;152(6):1304-12.

20. Leonardi CL, Powers JL, Matheson RT, et al; Etanercept Psoriasis Study Group. Etanercept as monotherapy in patients with psoriasis. N Engl J Med. 2003;349(21):2014-22.

21. Menter A, Tyring SK, Gordon K, et al. Adalimumab therapy for moderate to severe psoriasis: a randomized, controlled phase III trial. J Am Acad Dermatol. 2008;58(1):106-15.

22. Menter A, Gordon KB, Leonardi CL, Gu Y, Goldblum OM. Efficacy and safety of adalimumab across subgroups of patients with moderate to severe psoriasis. J Am Acad Dermatol. 2010;63(3):448-56. 
23. Reich K, Nestle FO, Papp K, et al.; EXPRESS study investigators. Infliximab induction and maintenance therapy for moderate-to-severe psoriasis: a phase III, multicentre, double-blind trial. Lancet. 2005;366 (9494):1367-74

24. Leonardi CL, Kimball AB, Papp KA, et al; PHOENIX 1 Study Investigators. Efficacy and safety of ustekinumab, a human interleukin-12/23 monoclonal antibody, in patients with psoriasis: 76-week results from a randomised, double-blind, placebo-controlled trial (PHOENIX 1). Lancet. 2008;371(9625):1665-74.

25. Papp KA, Langley RG, Lebwohl M, et al; PHOENIX 2 Study Investigators. Efficacy and safety of ustekinumab, a human interleukin-12/23 monoclonal antibody, in patients with psoriasis: 52-week results from a randomised, double-blind, placebo-controlled trial (PHOENIX 2). Lancet. 2008;371(9625):1675-84.

26. Krueger GG, Papp KA, Stough DB, Loven KH, Gulliver WP, Ellis CN; Alefacept Clinical Study Group. A randomized, double-blind, placebocontrolled phase III study evaluating efficacy and tolerability of 2 courses of alefacept in patients with chronic plaque psoriasis. J Am Acad Dermatol. 2002;47(6):821-33.

27. Wu E, Chen L, Birnbaum H, Yang E, Cifaldi M. Retrospective claims data analysis of dosage adjustment patterns of TNF antagonists among patients with rheumatoid arthritis. Curr Med Res Opin. 2008;24(8):2229-40.

28. Huang X, Gu NY, Fox KM, Harrison DJ, Globe D. Comparison of methods for measuring dose escalation of the subcutaneous TNF antagonists for rheumatoid arthritis patients treated in routine clinical practice. Curr Med Res Opin. 2010;26(7):1637-45.
29. Ollendorf DA, Klingman D, Hazard E, Ray S. Differences in annual medication costs and rates of dosage increase between tumor necrosis factorantagonist therapies for rheumatoid arthritis in a managed care population. Clin Ther. 2009;31(4):825-35.

30. Bonafede M, Gandra SR, Watson C, Princic N, Fox KM. Cost per treated patient for etanercept, adalimumab, and infliximab across adult indications: a claims analysis. Adv Ther. 2012;29(3):234-48

31. Schabert VF, Watson C, Gandra SR, Goodman S, Fox KM, Harrison DJ. Annual costs of tumor necrosis factor inhibitors using real-world data in a commercially insured population in the United States. J Med Econ. 2012;15(2):264-75.

32. Schabert VF, Watson C, Joseph GJ, Iversen P, Burudpakdee C, Harrison DJ. Costs of tumor necrosis factor blockers per treated patient using real-world drug data in a managed care population. J Manag Care Spec Pharm. 2013;19(8):621-30. Available at: http://www.amcp.org/WorkArea/ DownloadAsset. aspx?id=17205.

33. Bonafede M, Fox KM, Watson C, Princic N, Gandra SR. Treatment patterns in the first year after initiating tumor necrosis factor blockers in realworld settings. Adv Ther. 2012;29(8):664-74.

34. Gniadecki R, Bang B, Bryld LE, Iversen L, Lasthein S, Skov L. Comparison of long-term drug survival and safety of biologic agents in patients with psoriasis vulgaris. Br J Dermatol. 2015;172(1):244-252.

35. van den Reek JM, Tummers M, Zweegers J, et al. Predictors of adalimumab drug survival in psoriasis differ by reason for discontinuation: long-term results from the Bio-CAPTURE registry. J Eur Acad Dermatol Venereol. 2014. August 4. [Epub ahead of print].

36. López-Ferrer A, Vilarrasa E, Gich IJ, Puig L. Adalimumab for the treatment of psoriasis in real life: a retrospective cohort of 119 patients at a single Spanish centre. Br J Dermatol. 2013;169(5):1141-47. 